\title{
Therapeutic effect of combined hyperbaric oxygen and radiation therapy for single brain metastasis and its influence on osteopontin and MMP-9
}

\author{
JING TAO $^{1}$, ZHAOYU GAO ${ }^{1}$, RUI HUANG ${ }^{2}$ and HONG LI ${ }^{1}$ \\ ${ }^{1}$ Department of Hyperbaric Oxygen Therapy, Affiliated Hongqi Hospital, Mudanjiang Medical University; \\ ${ }^{2}$ Department of Academic Theory, Mudanjiang Medical University, Mudanjiang, Heilongjiang 157011, P.R. China
}

Received April 4, 2017; Accepted June 15, 2018

DOI: $10.3892 /$ etm.2018.6930

\begin{abstract}
The present study aimed to investigate the therapeutic effect of combined hyperbaric oxygen and radiation therapy for the treatment of single brain metastasis (SBM), as well as its influence on osteopontin (OPN) and matrix metalloproteinase-9 (MMP-9). A total of 86 patients with SBM were admitted to Hongqi Hospital from January 2013 to January 2016 and those included within the study were randomly divided into two groups. The control group was only treated with whole brain radiotherapy, while the observation group was treated with hyperbaric oxygenation combined with whole brain radiotherapy. OPN and MMP-9 expression was measured in each group by ELISA and the results prior to and following treatment were compared. The total effective rate (patients with complete remission, partial remission or stabilized lesions) in the observation group $(95.3 \%)$ was significantly increased compared with the control group (67.4\%). However, the OPN and MMP-9 protein levels observed in the observation group were significantly reduced compared with the control group $(\mathrm{P}<0.05)$. In addition, the quality of life and the incidence of adverse reactions in the observation group were significantly improved compared with the control group $(\mathrm{P}<0.05)$. For patients with SBM, hyperbaric oxygenation combined with radiotherapy may improve the efficiency of treatment and should be considered for further investigation and use within a clinical setting.
\end{abstract}

Correspondence to: Dr Hong Li, Department of Hyperbaric Oxygen Therapy, Affiliated Hongqi Hospital, Mudanjiang Medical University, 3 Tong Xiang Street, Mudanjiang, Heilongjiang 157011, P.R. China

E-mail: suntao0917@163.com

Key words: hyperbaric oxygenation therapy, radiotherapy, single brain metastases, osteopontin, matrix metalloproteinase- 9

\section{Introduction}

Brain metastases are malignant tumors in the brain, which have been transferred from other organs; the majority are originally transferred from the lungs and these tumors make up 20-40\% of all brain metastases (1). Patients with brain metastases typically have a poor prognosis (1-year overall survival rate of $\sim 60 \%$ ) (2), however combined modality therapy may improve their overall survival rate (3). A combination of hyperbaric oxygen (HBO) and radiation therapy may improve the therapeutic outcomes of radiotherapy (4). It has been previously documented that hypoxic cells in malignant tumors demonstrate low radiosensitivity, which reduces the effectiveness of traditional radiation therapy and may even cause radiation-derived brain damage (4). HBO is a type of therapy using high-concentration oxygen to treat hypoxic diseases (5). HBO has been widely used to treat brain diseases, including brain contusion, peripheral nerve injury, brain embolism, cerebral blood supply insufficiency and polyneuritis (6). Several case reports have suggested that HBO is an important therapeutic option for the treatment of brain metastasis, which leads to the improvement of neurologic symptoms, decreased steroid requirement and reduced lesion size on imaging $(5,7)$. Radiation therapy for brain metastasis may be more effective when combined with HBO pre-treatment, which may alter the microenvironment of the malignant tumor. However, to the best of our knowledge, there is currently no data that systematically compares the effect of HBO pre-treatment, or supports its positive effects on radiotherapy directed against brain metastases.

Osteopontin (OPN) is an adhesive glycoprotein associated with adhesion and metastasis in cancer cells (8). Matrix metalloproteinase (MMP)-9 is a member of the MMP family, which is involved in the degradation of the extracellular matrix and metastasis $(9,10)$. MMP-9 has been reported to promote the metastasis of breast cancer to the brain (11). It has also been reported that the expression of MMP-9 and OPN are correlated $(11,12)$ and that OPN may promote metastasis by influencing MMP-9. It has been previously reported that OPN may promote gastric cancer metastasis through protein kinase B-mediated hypoxia-inducible factor-1a upregulation and MMP-9 activation (13). Rangaswami and Kundu (14) 
revealed that OPN stimulates melanoma growth and lung metastasis through the activation of nuclear factor (NF) inducing kinase/mitogen-activated protein kinase kinase kinase 1-dependent MMP-9 signaling pathways. Another study revealed that OPN promotes tumor cell invasion of hepatocellular carcinoma by activating MMP-9 through the NF- $\mathrm{B}$ signaling pathway (12). Additionally, OPN and MMP-9 are considered biomarkers for monitoring cancer progression $(11,15,16)$. OPN is also a biomarker for microglial activation and brain injury (17). MMP-9 is increased in the brain and plasma of neonatal mice as well as in the plasma of neonatal humans following hypoxia-ischemia (18).

In the present study, a combination of hyperbaric oxygenation and radiation therapy was used to treat patients with single brain metastasis (SBM). The method created an atmosphere of high-concentration oxygen for the hypoxic cells, which enhanced their radiosensitivity and improved the effect of radiation therapy. In addition this also protected the patient's brain tissue. The expression levels of OPN and MMP-9 were detected as they are associated with tumor infiltration, tumor metastasis and overall clinical prognosis. The present study aimed to assess the effectiveness of combination therapy for the treatment of brain metastasis.

\section{Patients and methods}

Patients. Patients with brain metastasis who presented at the Affiliated Hongqi Hospital of Mudanjiang Medical University (Mudanjiang, China) from January 2013 to January 2016 were considered as participants for the present study. If the patient exhibited hemorrhage, pneumothorax, mediastinal emphysema, or pulmonary bullae, they were excluded from the current study. Patients were also excluded from the results if they became unconscious or died during treatment. The inclusion criteria were follows: Patients who were diagnosed with SBM by magnetic resonance imaging (MRI) or computerized tomography (CT) and patients who voluntarily accepted the random grouping of the study. A total of 86 patients were recruited into the study, including 49 males and 37 females. Participants were 21-76 years old with an average age of $53.8 \pm 7.9$ years. The patients were randomly divided into the control group and the observation group ( $n=43 /$ group). During the three courses of HBO treatment, the patients in observation group received palliative chemotherapy $(19,20)$. The present study was approved by the Ethics Committee of Mudanjiang Medical University and informed consent was obtained from all patients.

Therapeutic regimen. The therapeutic method (Palliative care) used in the present study was the same as previously described (21,22). Patients in the control group were treated using a PRIMUS ${ }^{\mathrm{TM}}$ linear accelerator $(6 \mathrm{MV}$; Siemens Healthineers, Erlangen, Germany) for X-ray isocenter irradiation at a dosage of $60 \mathrm{~Gy}, 2$ Gy/total dose (DT), 40 Gy 20 times followed by local irradiation at $20 \mathrm{~Gy} / \mathrm{DT}, 20 \mathrm{~Gy} 10$ times. Patients in the observation group were treated with $\mathrm{HBO}$ for 90 min prior to each radiation treatment. An HBO chamber (Shanghai 701 Yang Garden Hyperdaric Oxygen Chamber Co. Ltd. (Shanghai, China) was used to increase the atmospheric pressure for the patients within a range of 0.20-0.25 $\mathrm{MPa}$ for
40-60 min. Simultaneously, oxygen masks were put over the patient's faces providing oxygen at a purity of $0.22-0.25 \mathrm{MPa}$. The patients inhaled oxygen for $60 \mathrm{~min}$. During the period of oxygen inhalation the patients rested for $10 \mathrm{~min}$ every $30 \mathrm{~min}$. Following the oxygen inhalation each patient had a decompression period of 20-25 min.

During the radiotherapy, patients in each group were administered dexamethasone (10 mg) and mannitol (20\%, $125 \mathrm{ml}$ ) to reduce their intracranial pressure. Each therapeutic course lasted for 10 days. The patients in each group were evaluated following 3 therapeutic courses to assess the curative effect. Primary tumors were assessed and graded as previously described (23), prior to and following treatment. The primary tumors were analyzed one week prior to the commencement of treatment and within 2 weeks following the completion of treatment.

ELISA. The expression levels of OPN and MMP-9 in the patient's plasma prior to and following treatment were measured by ELISA. A total of $4 \mathrm{ml}$ peripheral blood was collected from all patients and human. The blood was then centrifuged for $15 \mathrm{~min}$ at $1940.5 \mathrm{x}$ g (Microfuge 20/20R; Beckman Coulter, Inc., Brea, CA, USA) at $37^{\circ} \mathrm{C}$. Human MMP-9 Quantikine ELISA kit (Type: Solid Phase Sandwich ELISA cat. no. E-EL-R0624c; R\&D Systems, Inc., Minneapolis, MN, USA) were used to measure the levels of OPN and MMP-9 according to the manufacturer's protocol (RayBiotech, Inc., Norcross, GA, USA). The optical density of OPN and MMP-9 were detected at a wavelength of $450 \mathrm{~nm}$ using a microplate reader (Thermo Fisher Scientific, Inc., Waltham, MA, USA). All samples were measured as technical duplicates and the protein levels were calculated from standard curves.

Curative effect evaluation. Following three therapeutic courses, the curative effects observed in each group were evaluated using CT images as previously reported (24). The correlation between radiologic and pathologic response by Response Evaluation Criteria In Solid Tumors 1.1 (25), Choi criteria (26) and modified Choi criteria (27) were retrospectively assessed. Patients whose tumors disappeared completely for $>1$ month were regarded as being in complete remission. Patients whose maximum tumor vertical diameter was reduced to $>50 \%$ of its original size, and who remained at their stage for $>1$ month were diagnosed as being in partial remission. When the tumor size was reduced by $<50 \%$ of its original size, when the tumor size had increased with a volume that did not exceed $25 \%$ of its original size or when the stage lasted for $>1$ month, the patients were diagnosed as stable. When the tumor size increased $>25 \%$ of its original size, the patients were regarded as having disease progression. All measurements were analyzed by two radiologists who were blinded to all clinical information to avoid bias. The effective rate was defined as the sum of the complete remission rate, partial remission rate and stabilized lesion rate.

The Quality of Life Questionnaire of The European Organization for Research and Treatment of Cancer, together with the mode of standard grading was employed prior to and 2 weeks following treatment (28). The patients with higher scores in the limb evaluation demonstrated a better limb function. Similarly, patients with higher scores on the symptom evaluation had a better quality of life. 


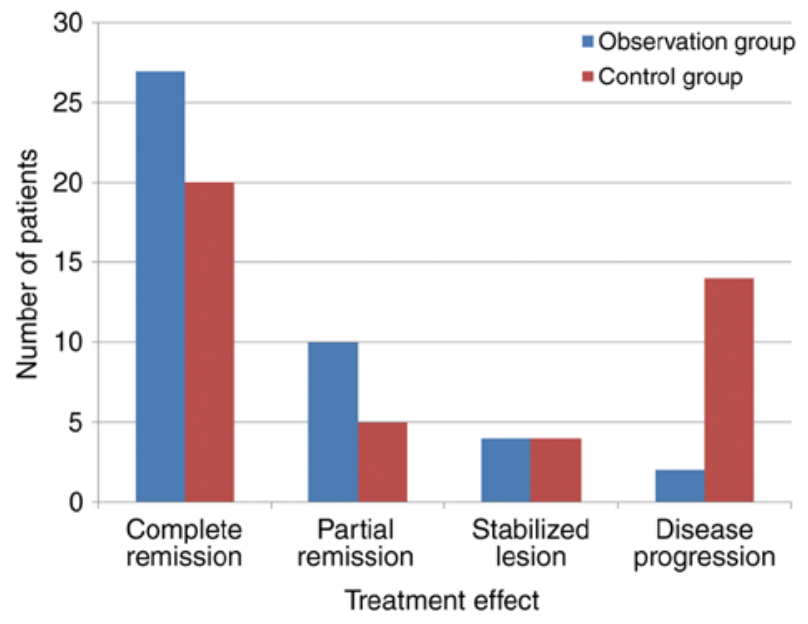

Figure 1. Comparison of the clinical effects of treatment in each group. In the observation group, the number of patients diagnosed with complete remission, partial remission, stabilized lesion and disease progression were 27, 10 , 4 and 2 , respectively, while they were $20,5,4$ and 14 , respectively in the control group.

The patients in each group were assessed for the development of acute brain injury as an adverse reaction to treatment. The acute brain injury was assessed by CT or MRI, in which large edema and other characteristics were observed beyond the SBM location.

Statistical analysis. SPSS version 19.0 (IBM Corp., Armonk, NY, USA) was used for statistical analysis. The data are presented as the mean \pm standard deviation. An F-test and chi-square test were used for the comparison of two data groups $(n=3)$. For the comparison of more than two groups, one-way analysis of variance with Holm-Sidak's multiple comparisons test was performed. $\mathrm{P}<0.05$ was considered to indicate a statistically significant difference.

\section{Results}

Comparable characteristics in the two treatment groups. To test the grouping rational, the general conditions of each group were determined and analyzed (Table I). There was no statistical difference in the sex and age between the two groups (Table I). Additionally, no statistical difference was observed between the two groups in their quality of life and expression of OPN and MMP-9 prior to the commencement of the experiment. Together, these results indicate that the group division was reasonable and that the two groups were comparable.

HBO may improve the effect of radiotherapy. To identify the efficiency of $\mathrm{HBO}$ in patients treated with radiotherapy, the curative effects between the two groups were compared (Fig. 1). The results revealed that the total effective rate of the observation group was $95.3 \%$ while in the control group it was $67.4 \%$, which was significantly reduced $(\mathrm{P}<0.05$; Table II). Further analysis revealed that there were no significant differences between the patient's primary cancer stages prior to and following treatment in the two groups (Table I), which suggests that the observed improvements in SBM were due to the effects of combined $\mathrm{HBO}$ and radiotherapy as opposed to cancer stage. In conclusion, the results demonstrated that $\mathrm{HBO}$ may improve the effects of radiotherapy.

$H B O$ reduces the repression of $O P N$ and $M M P-9$. To examine the molecular mechanism by which HBO may improve radiotherapy efficiency, the expression of OPN and MMP-9 was measured in each of the groups following treatment. Prior to treatment there were no statistical differences between the expression of OPN and MMP-9 in each group (Table I). Following treatment the expressions of OPN and MMP-9 in each group had significantly decreased in comparison to their levels prior to treatment $(\mathrm{P}<0.001$; Table III). In addition, the expression of OPN and MMP-9 in the observation group were significantly reduced in comparison with the control group following treatment $(\mathrm{P}<0.001$; Table III). These results suggest that $\mathrm{HBO}$ improves the efficiency of radiotherapy by reducing the expression of OPN and MMP-9.

HBO may improve the quality of life in patients with SBM receiving radiotherapy. To further characterize the effect of $\mathrm{HBO}$, the quality of life in each group was compared. The quality of life assessment of the patients prior to treatment indicated that there were no significant differences in the functions and symptoms between the two groups (Table I). Following treatment, the quality of life (functions and symptoms) in the observation group was significantly improved compared with the control group $(\mathrm{P}<0.05$; Table IV). These results suggest that HBO may improve the quality of life in patients with SBM receiving radiotherapy.

HBO may reduce adverse reactions. To study the development of adverse reactions, the long-term curative effect was observed and compared between the two groups. A total of 15 out of 43 patients in the control group suffered from acute brain injury and the incidence rate of adverse reactions was $34.9 \%$ (Table V). In contrast, only 5 out of 43 patients in the observation group suffered from acute brain injury and the incidence rate of adverse reactions was $11.6 \%$. The incidence rate of adverse reactions was significantly reduced in the observation group compared with the control group $(\mathrm{P}<0.05$; Table V). These results suggest that HBO may reduce adverse reactions in patients treated with radiotherapy.

\section{Discussion}

Brain metastasis is typically caused by the transfer of primary tumors, including small cell lung cancer, breast cancer, lung adenocarcinoma, rectal cancer and colon cancer, to the brain (29). Although radiotherapy is widely used within clinics to treat brain metastasis, low radiosensitivity of hypoxic cells in tumor tissues often leads to unsatisfactory curative rates. In addition, radiotherapy may induce radiation damage to the patient's brain and cause other adverse reactions (30). It has been previously reported that the microenvironment of tumor tissues changes under hypoxic conditions, which means that hypoxic stress may prompt the tumor cells to increase their attacking ability and accelerate their own proliferation rate (31). In addition, genetic mutations occurred repeatedly in tumor cells, which may cause enhanced cell metabolism and accelerate glycolysis and angiogenesis (32). These changes 
Table I. General condition of participants in the two groups prior to treatment.

\begin{tabular}{|c|c|c|c|c|c|}
\hline \multirow[b]{2}{*}{ Characteristic } & \multirow[b]{2}{*}{ Observation group } & \multirow[b]{2}{*}{ Control group } & \multicolumn{2}{|c|}{ Statistical test } & \multirow[b]{2}{*}{ P-value } \\
\hline & & & F test & $\chi^{2}$ & \\
\hline Age & $53.75 \pm 8.99$ & $51.35 \pm 6.79$ & 1.971 & - & 0.165 \\
\hline Sex & & & 1.253 & 0.05 & 0.826 \\
\hline Male & 26 & 25 & & & \\
\hline Female & 17 & 18 & & & \\
\hline Primary cancer type & & & 0.654 & 0.81 & 0.990 \\
\hline Gastric & 2 & 3 & & & \\
\hline Lung & 31 & 29 & & & \\
\hline Breast & 3 & 4 & & & \\
\hline Esophageal & 1 & 1 & & & \\
\hline Liver & 2 & 3 & & & \\
\hline Colon & 1 & 1 & & & \\
\hline Other & 3 & 2 & & & \\
\hline Treatment for primary cancer & $\begin{array}{c}\text { Palliative } \\
\text { chemotherapy }\end{array}$ & $\begin{array}{c}\text { Palliative } \\
\text { chemotherapy }\end{array}$ & & & \\
\hline Primary cancer stage & & & 0.203 & 1.50 & 0.240 \\
\hline Prior to treatment & III $(n=43)$ & III (n=43) & & & \\
\hline \multirow[t]{2}{*}{ Post treatment } & III $(n=41)$ & III $(n=38)$ & & & \\
\hline & IV $(n=2)$ & IV $(n=5)$ & & & \\
\hline Osteopontin expression $\left(\mathrm{mg} \cdot \mathrm{l}^{-1}\right)$ & $5.94 \pm 0.52$ & $5.77 \pm 0.31$ & 0.872 & - & 0.072 \\
\hline Matrix metalloproteinase-9 expression $\left(\mathrm{mg} \cdot \mathrm{l}^{-1}\right)$ & $5.61 \pm 0.75$ & $5.39 \pm 1.27$ & 0.756 & - & 0.160 \\
\hline \multicolumn{6}{|l|}{ Function } \\
\hline Physical & $63.4 \pm 17.6$ & $63.9 \pm 16.7$ & 5.364 & - & 0.893 \\
\hline Emotional & $39.9 \pm 13.7$ & $39.2 \pm 14.0$ & 6.231 & - & 0.815 \\
\hline Social & $32.0 \pm 26.7$ & $34.3 \pm 29.0$ & 3.138 & - & 0.703 \\
\hline Cognitive & $73.2 \pm 21.7$ & $74.9 \pm 19.6$ & 2.348 & - & 0.704 \\
\hline Holistic health & $42.6 \pm 17.6$ & $44.9 \pm 18.9$ & 1.568 & - & 0.561 \\
\hline \multicolumn{6}{|l|}{ Symptoms } \\
\hline Nausea and vomiting & $94.9 \pm 5.3$ & $96.1 \pm 4.7$ & 4.712 & - & 0.265 \\
\hline Fatigue & $67.4 \pm 20.9$ & $69.6 \pm 21.2$ & 0.849 & - & 0.629 \\
\hline Pain & $54.3 \pm 19.8$ & $55.4 \pm 23.7$ & 2.122 & - & 0.816 \\
\hline Insomnia & $43.9 \pm 26.7$ & $46.7 \pm 20.4$ & 1.245 & - & 0.586 \\
\hline Appetite loss & $42.1 \pm 14.9$ & $44.3 \pm 15.7$ & 1.967 & - & 0.507 \\
\hline
\end{tabular}

OPN, osteopontin; MMP, matrix metalloproteinase.

Table II. Comparison of the clinical effects observed in the two groups.

\begin{tabular}{lcccc}
\hline Treatment was effective & Observation group & Control group & $\chi^{2}$ & P-value \\
\hline Yes & 41 & 35 & 4.07 & 0.044 \\
No & 2 & 8 & \\
\hline
\end{tabular}

often have a negative impact on the effectiveness of radiation therapy.

Therefore, the present study investigated the method of combined HBO and radiotherapy to treat patients with brain metastasis. It has been previously reported that $\mathrm{HBO}$ treatment alone has no positive effects for the treatment of brain metastasis, and may even cause brain damage by developing oxygen-rich conditions (33). Therefore, in the present study, the patients took regular breaks as part of the $\mathrm{HBO}$ treatment to minimize the risk of adverse effects; the patients oxygen pressure was restored to normal for $10 \mathrm{~min}$ every $30 \mathrm{~min}$. In addition, the lowering speed of oxygen partial pressure in 
Table III. Comparison of the OPN and MMP-9 values in the two groups prior to and following treatment $(n=43)$.

\begin{tabular}{|c|c|c|c|c|}
\hline \multirow[b]{2}{*}{ Plasma component } & \multicolumn{2}{|c|}{ Observation group } & \multicolumn{2}{|c|}{ Control group } \\
\hline & Prior to treatment & Post treatment & Prior to treatment & Post treatment \\
\hline $\mathrm{OPN}\left(\mathrm{mg} \cdot \mathrm{l}^{-1}\right)$ & $5.94 \pm 0.52$ & $4.02 \pm 0.56^{\mathrm{a}, \mathrm{b}}$ & $5.77 \pm 0.31$ & $4.93 \pm 0.46^{\mathrm{c}}$ \\
\hline $\operatorname{MMP}-9\left(\mathrm{mg} \cdot \mathrm{l}^{-1}\right)$ & $5.66 \pm 0.69$ & $4.01 \pm 0.66^{\mathrm{a}, \mathrm{b}}$ & $5.39 \pm 1.28$ & $4.94 \pm 0.81^{\mathrm{c}}$ \\
\hline
\end{tabular}

OPN, osteopontin; MMP-9, matrix metalloproteinase-9. ${ }^{a} \mathrm{P}<0.001 \mathrm{vs}$. the observation group prior to treatment. ${ }^{b} \mathrm{P}<0.001 \mathrm{vs}$. the control group post treatment. ${ }^{\mathrm{C}} \mathrm{P}<0.001 \mathrm{vs}$. the control group prior to treatment.

Table IV. Comparison of the patient's life quality between the two groups.

\begin{tabular}{|c|c|c|c|c|}
\hline Characteristic & Control group & Observation group & F test & P-value \\
\hline \multicolumn{5}{|l|}{ Function } \\
\hline Physical & $48.9 \pm 17.6$ & $69.9 \pm 14.3$ & 6.072 & $<0.001$ \\
\hline Emotional & $49.7 \pm 24.3$ & $71.9 \pm 20.3$ & 4.598 & $<0.001$ \\
\hline Social & $35.1 \pm 29.9$ & $55.9 \pm 32.7$ & 3.078 & 0.003 \\
\hline Cognitive & $75.9 \pm 19.8$ & $86.0 \pm 19.7$ & 2.371 & 0.020 \\
\hline Holistic health & $46.1 \pm 12.0$ & $59.5 \pm 15.4$ & 4.501 & $<0.001$ \\
\hline \multicolumn{5}{|l|}{ Symptom } \\
\hline Nausea and vomiting & $84.9 \pm 12.3$ & $68.7 \pm 13.1$ & 5.912 & $<0.001$ \\
\hline Fatigue & $65.4 \pm 19.6$ & $51.2 \pm 18.5$ & 3.455 & 0.001 \\
\hline Pain & $69.9 \pm 13.2$ & $57.1 \pm 9.7$ & 5.124 & $<0.001$ \\
\hline Insomnia & $57.4 \pm 18.7$ & $46.3 \pm 16.4$ & 2.926 & 0.004 \\
\hline Appetite loss & $62.0 \pm 10.7$ & $49.9 \pm 8.7$ & 5.754 & $<0.001$ \\
\hline
\end{tabular}

Table V. Comparison of the adverse reactions between the two groups.

\begin{tabular}{lccr}
\hline Adverse reactions & Observation group (\%) & Control group (\%) & $\chi^{2}$ \\
\hline Yes & $5(11.6)$ & $15(34.9)$ & 6.52 \\
No & $38(88.4)$ & $28(65.1)$ & 0.011 \\
\hline
\end{tabular}

tumor cells is reduced compared with normal tissues, so it is necessary to perform radiotherapy at a higher oxygen content. It was observe that this method improved the effect of radiation therapy, as well as protecting the normal tissues. The results revealed that the effective rate in the observation group was $95.3 \%$, which was significantly increased compared with the control group (67.4\%). In addition, following three therapeutic courses the patient's quality of life scores were significantly increased in the observation group compared with the control group. The number of radiation-induced brain injuries in the observation group was significantly reduced compared with the control group, which further supported the positive effect of combination therapy.

In the present study, the effects of combined radiotherapy and $\mathrm{HBO}$ were investigated. Several other previous studies have also suggested that a combined approach, if feasible, should be recommended for the treatment of brain metastasis $(34,35)$. Surgery followed by radiotherapy may be an effective treatment option for selected patients with single, large brain metastases from solid tumors (36-38). Tumor volume, neurological symptoms, age and previous whole brain radiation therapy have also been demonstrated to be prognostic for the outcome of patients with SBM (39). These results suggest that treatment of SBM is very complex and proper methods should be carefully selected, as a number of factors could affect the outcome.

OPN and MMP-9 serve key roles in the development and metastasis of tumors, and promote the adhesion, chemotaxis and migration of tumor cells and the degradation of the extracellular matrix (40). OPN and MMP-9 are closely linked to the infiltration and metastasis of tumors $(41,42)$. According to a previous study, OPN and MMP-9 are significantly increased in brain metastatic tumors compared with normal tissues (43). Therefore, these two genes may be used as biomarkers for tumor lymphatic metastasis. The present research indicated that there was no significant difference in the expression of OPN and MMP-9 between the experimental and control groups prior to treatment. However, following three therapeutic courses, the expression of OPN and MMP-9 was significantly reduced compared with prior 
to treatment in each group $(\mathrm{P}<0.05)$. It was observed that each treatment method effectively inhibited the progression of tumor metastasis and infiltration. However, the expression of OPN and MMP-9 was significantly reduced in the observation group compared with the control group $(\mathrm{P}<0.05)$. This result supports the hypothesis that combination therapy is more effective than radiotherapy alone. The authors considered that it was primarily due to improved radiosensitivity of the tumor tissues through $\mathrm{HBO}$, which then reduced tumor proliferation and metastasis.

In conclusion, combining $\mathrm{HBO}$ with radiotherapy may enhance the effectiveness of radiotherapy for brain metastasis, improve the patient's quality of life and reduce tumor metastasis and infiltration. In addition it may also decrease the incidence of radiation-induced brain injury. Based on these findings, combination therapy is worthy of further investigation and has potential for implementation within a clinical setting.

\section{Acknowledgements}

Not applicable.

\section{Funding}

No funding was received.

\section{Availability of data and materials}

The datasets used and/or analyzed during the current study are available from the corresponding author on reasonable request.

\section{Authors' contributions}

JT collected clinical information and wrote the manuscript. $\mathrm{ZG}$ and RH also collected the data. HL designed the present study and critically reviewed the manuscript. All authors approved the final manuscript and agree to be accountable for all aspects of the present study.

\section{Ethics approval and consent to participate}

The present study was approved by the Ethics Committee of Mudanjiang Medical University and written informed consent was obtained from the cohort.

\section{Patient consent for publication}

Not applicable.

\section{Competing interests}

The authors declare that they have no competing interests.

\section{References}

1. Ukawa M, Fujiwara Y, Ando H, Shimizu T and Ishida T: Hepatic tumor metastases cause enhanced PEGylated liposome uptake by Kupffer cells. Biol Pharm Bull 39: 215-220, 2016.

2. Balermpas P, Stera S, Müller von der Grün J, Loutfi-Krauss B, Forster MT, Wagner M, Keller C, Rödel C, Seifert V, Blanck O and Wolff R: Repeated in-field radiosurgery for locally recurrent brain metastases: Feasibility, results and survival in a heavily treated patient cohort. PLoS One 13: e0198692, 2018.
3. Kotecha R, Suh JH, Barnett GH, Murphy ES, Ahluwalia M, Reddy CA, Vogelbaum MA, Angelov L, Mohammadi AM, Stevens GHJ, et al: Changing trends in brain metastasis: A 20-year review of patient outcomes. Int J Radiat Oncol Biol Phys 96: E518, 2016.

4. Zheng R, Yao Q, Xie G, Du S, Ren C, Wang Y, Yuan Y: TAT-ODD-p53 enhances the radiosensitivity of hypoxic breast cancer cells by inhibiting Parkin-mediated mitophagy. Oncotarget 6: 17417-17429, 2015.

5. Stępień K, Ostrowski RP and Matyja E: Hyperbaric oxygen as an adjunctive therapy in treatment of malignancies, including brain tumours. Med Oncol 33: 101, 2016.

6. Leber KA, Eder HG, Kovac H, Anegg U and Pendl G: Treatment of cerebral radionecrosis by hyperbaric oxygen therapy. Stereotact Funct Neurosurg 70: 229-236, 1998.

7. Ohguri T, Imada H, Kohshi K, Kakeda S, Ohnari N, Morioka T, Nakano K, Konda N and Korogi Y: Effect of prophylactic hyperbaric oxygen treatment for radiation-induced brain injury after stereotactic radiosurgery of brain metastases. Int J Radiat Oncol Biol Phys 67: 248-255, 2007.

8. Cosse JP and Michiels C: Tumour hypoxia affects the responsiveness of cancer cells to chemotherapy and promotes cancer progression. Anticancer Agents Med Chem 8: 790-797, 2008.

9. Deryugina EI and Quigley JP: Matrix metalloproteinases and tumor metastasis. Cancer Metastasis Rev 25: 9-34, 2006.

10. Mendes O, Kim HT and Stoica G: Expression of MMP2, MMP9 and MMP3 in breast cancer brain metastasis in a rat model. Clin Exp Metastasis 22: 237-246, 2005.

11. Castellano G, Malaponte G, Mazzarino MC, Figini M, Marchese F, Gangemi P, Travali S, Stivala F, Canevari S and Libra M: Activation of the osteopontin/matrix metalloproteinase-9 pathway correlates with prostate cancer progression. Clin Cancer Res 14: 7470-7480, 2008.

12. Takafuji V, Forgues M, Unsworth E, Goldsmith P and Wang XW: An osteopontin fragment is essential for tumor cell invasion in hepatocellular carcinoma. Oncogene 26: 6361-6371, 2007.

13. Song G, Ouyang G, Mao Y, Ming Y, Bao S and Hu T: Osteopontin promotes gastric cancer metastasis by augmenting cell survival and invasion through Akt-mediated HIF-1alpha up-regulation and MMP9 activation. J Cell Mol Med 13: 1706-1718, 2009.

14. Rangaswami Hand Kundu GC: Osteopontin stimulates melanoma growth and lung metastasis through NIK/MEKK1-dependent MMP-9 activation pathways. Oncol Rep 18: 909-915, 2007.

15. Kerenidi T, Kazakou AP, Lada M, Tsilioni I, Daniil Z and Gourgoulianis KI: Clinical significance of circulating osteopontin levels in patients with lung cancer and correlation with VEGF and MMP-9. Cancer Invest 34: 385-392, 2016.

16. Wei R, Wong JPC and Kwok HF: Osteopontin-a promising biomarker for cancer therapy. J Cancer 8: 2173-2183, 2017.

17. Li Y, Dammer EB, Zhang-Brotzge X, Chen S, Duong DM, Seyfried NT, Kuan CY and Sun YY: Osteopontin is a blood biomarker for microglial activation and brain injury in experimental hypoxic-ischemic encephalopathy. eNeuro 4: ENEURO.0253-16.2016, 2017.

18. Bednarek N, Svedin P, Garnotel R, Favrais G, Loron G, Schwendiman L, Hagberg H, Morville P, Mallard C and Gressens P: Increased MMP-9 and TIMP-1 in mouse neonatal brain and plasma and in human neonatal plasma after hypoxia-ischemia: A potential marker of neonatal encephalopathy. Pediatr Res 71: 63-70, 2012.

19. Lin J,Huang SM, Zhu J, Chen SM, Chen WX, Wu GG and Zhao TX: Kangai injection and palliative treatment of hepatocellular carcinoma and survival analysis in patients with advanced hepatocellular carcinoma. Zhongjua Zhong Yi Yuan Xue Kan 36: 1278-1280, 2018 (In Chinese).

20. Chen CX, Wang YW, Yu HY, Wu XH and Fan XL: Effects of palliative treatment on short-term quality of life improvement in patients with advanced malignant tumors. Huli Shijian Yu Yanjiu 15: 98-100, 2018 (In Chinese).

21. van der Bel R, Sliggers BC, van Houwelingen MJ, van Lieshout JJ, Halliwill JR, van Hulst RA and Krediet CT: A modified device for continuous non-invasive blood pressure measurements in humans under hyperbaric and/or oxygen-enriched conditions. Diving Hyperb Med 46: 38-42, 2016.

22. Mazanec $\mathrm{P}$ and Prince-Paul M: Integrating palliative care into active cancer treatment. Semin Oncol Nurs 30: 203-211, 2014.

23. Chan DL, Pavlakis N, Schembri GP, Bernard EJ, Hsiao E, Hayes A, Barnes T, Diakos C, Khasraw M, Samra J, et al: Dual somatostatin receptor/FDG PET/CT imaging in metastatic neuroendocrine tumours: Proposal for a novel grading scheme with prognostic significance. Theranostics 7: 1149-1158, 2017. 
24. Shinagare AB, Barysauskas CM, Braschi-Amirfarzan $M$, O'Neill AC, Catalano PJ, George S and Ramaiya NH: Comparison of performance of various tumor response criteria in assessment of sunitinib activity in advanced gastrointestinal stromal tumors. Clin Imaging 40: 880-884, 2016.

25. Eisenhauer EA, Therasse P, Bogaerts J, Schwartz LH, Sargent D, Ford R, Dancey J, Arbuck S, Gwyther S, Mooney M, et al: New response evaluation criteria in solid tumours: Revised RECIST guideline (version 1.1). Eur J Cancer 45: 228-247, 2009.

26. Choi H, Charnsangavej C, Faria SC, Macapinlac HA, Burgess MA, Patel SR, Chen LL, Podoloff DA and Benjamin RS: Correlation of computed tomography and positron emission tomography in patients with metastatic gastrointestinal stromal tumor treated at a single institution with imatinib mesylate: Proposal of new computed tomography response criteria. J Clin Oncol 25: 1753-1759, 2007.

27. Stacchiotti S, Verderio P, Messina A, Morosi C, Collini P, Llombart-Bosch A, Martin J, Comandone A, Cruz J, Ferraro A, et al: Tumor response assessment by modified Choi criteria in localized high-risk soft tissue sarcoma treated with chemotherapy. Cancer 118: 5857-5866, 2012.

28. Greimel ER, Kuljanic Vlasic K, Waldenstrom AC, Duric VM, Jensen PT, Singer S, Chie W, Nordin A, Bjelic Radisic V and Wydra D; European Organization for Research and Treatment of Cancer Quality-of-Life Group: The European Organization for Research and Treatment of Cancer (EORTC) quality-of-life questionnaire cervical cancer module: EORTC QLQ-CX24. Cancer 107: 1812-1822, 2006.

29. Smith A, Odronic S, Springer B and Reynolds J: Solid tumor metastases to the pancreas diagnosed by fine needle aspiration: A single institution experience and a review of the literature. J Am Soc Cytopathol 3: S72, 2014.

30. Kucharzewska P, Christianson HC, Welch JE, Svensson KJ, Fredlund E, Ringnér M, Mörgelin M, Bourseau-Guilmain E, Bengzon $\mathrm{J}$ and Belting M: Exosomes reflect the hypoxic status of glioma cells and mediate hypoxia-dependent activation of vascular cells during tumor development. Proc Natl Acad Sci USA 110: 7312-7317, 2013.

31. Martin R, Srivastava T, Lee J, Raj N, Koth KA and Whelan HT: Using hyperbaric oxygen for autism treatment: A review and discussion of literature. Undersea Hyperb Med 42: 353-359, 2015

32. Higdon B, Youngman L, Regehr M and Chiou A: Deep frostbite treated with hyperbaric oxygen and thrombolytic therapies. Wounds 27: 215-223, 2015.

33. Huang ET, Mansouri J, Murad MH, Joseph WS, Strauss MB, Tettelbach W and Worth ER; UHMS CPG Oversight Committee: A clinical practice guideline for the use of hyperbaric oxygen therapy in the treatment of diabetic foot ulcers. Undersea Hyperb Med 42: 205-247, 2015.
34. Yahara K, Ohguri T, Udono H, Yamamoto J, Tomura K, Onoda T, Imada H, Nishizawa S and Korogi Y: Radiotherapy using IMRT boosts after hyperbaric oxygen therapy with chemotherapy for glioblastoma. J Radiat Res 58: 351-356, 2017.

35. Halle B, Andersen C, Schulz MK and Kristensen BW: New glioma therapy using specific microRNAs. Ugeskr Laeger 174: 630-633, 2012 (In Danish).

36. Navarria P, Pessina F, Ascolese A, Cozzi L, Tomatis S, Riva M, Bello L, Clerici E, Lobefalo F and Scorsetti M: P13.11 Outcome evaluation of oligometastatic patients with single, large brain metastases treated with gross total resection (GTR) followed by hypofractionated stereotactic radiosurgery (HSRS) on the tumor bed. Neuro Oncol 18: iv71, 2016.

37. Kępka L, Tyc-Szczepaniak D, Bujko K, Olszyna-Serementa M, Michalski W, Sprawka A, Trąbska-Kluch B, Komosińska K, Wasilewska-Teśluk E and Czeremszyńska B: Stereotactic radiotherapy of the tumor bed compared to whole brain radiotherapy after surgery of single brain metastasis: Results from a randomized trial. Radiother Oncol 121: 217-224, 2016

38. Igaki H, Harada K, Umezawa R, Miyakita Y, Ohno M, Takahashi M, Sumi M, Inaba K, Murakami N, Ito Y, et al: Outcomes of surgery followed by local brain radiotherapy compared with surgery followed by whole brain radiotherapy for single brain metastasis. Tumori 103: 367-373, 2017.

39. Bennett EE, Angelov L, Vogelbaum MA, Barnett GH, Chao ST, Murphy ES, Yu JS, Suh JH, Jia X, Stevens GHJ, et al: The prognostic role of tumor volume in the outcome of patients with single brain metastasis after stereotactic radiosurgery. World Neurosurg 104: 229-238, 2017.

40. Ogbureke KU, Weinberger PM, Looney SW, Li L and Fisher LW: Expressions of matrix metalloproteinase-9 (MMP-9), dentin sialophosphoprotein (DSPP), and osteopontin (OPN) at histologically negative surgical margins may predict recurrence of oral squamous cell carcinoma. Oncotarget 3: 286-298, 2012.

41. Yang W, Lu J, Yang L and Zhang J: Association of matrix metalloproteinase-9 gene $-1562 \mathrm{C} / \mathrm{T}$ polymorphism with essential hypertension: A systematic review and meta-analysis article. Iran J Public Health 44: 1445-1452, 2015.

42. Rittling SR and Singh R: Osteopontin in immune-mediated diseases. J Dent Res 94: 1638-1645, 2015.

43. Wu LZ, Liu XL and Xie QZ: Osteopontin facilitates invasion in human trophoblastic cells via promoting matrix metalloproteinase-9 in vitro. Int J Clin Exp Pathol 8: 14121-14130, 2015. 